\title{
Hip Hop como proposta de trabalho na Educação Física Escolar: uma experiência no ensino médio do Colégio de Aplicação da UFRGS
}

\author{
Josias Góis Soares* \\ Carla da Conceição Lettnin ${ }^{* *}$
}

\begin{abstract}
Resumo: Este relato de experiência objetivou abordar o Hip Hop como um conteúdo possível nas aulas de Educação Física. Os alunos demonstraram-se motivados e envolvidos com o trabalho realizado devido à aplicabilidade e o significado desse conteúdo à vida deles. Dessa forma, os conteúdos assimilados pelos alunos foram muito além do que o planejamento propôs. As aulas eram frequentadas com espontaneidade, efetividade e alegria, preocupando-se com o processo e não com o produto. Como qualquer conteúdo curricular, se presta a formação integral do indivíduo na medida em que trabalha com aspectos históricoculturais, explora o movimento criativo, o conhecimento do corpo e de si, desafia o respeito às diferenças e as limitações, trabalha diferentes ritmos. Portanto, diante da riqueza que esse conteúdo é capaz de desenvolver identificam-se aqui alguns conceitos importantes, tais como: saúde, bem estar, felicidade, preconceito, solidariedade, limites.
\end{abstract}

Palavras-chave: Hip Hop, Ensino Médio, Educação Física, Educação.

\footnotetext{
Licenciado em Educação Física pela ESEF/UFRGS. E-mail: neguro5@gmail.com Professora da Área de Educação Física do Departamento de Expressão e Movimento do Colégio de Aplicação. Doutoranda do PPG em Educação da PUCRS. E-mail: carla.lettnin@ufrgs.br
} 


\begin{abstract}
This experience report aimed to address the Hip Hop as a possible content in physical education classes. Students showed up motivated and commitment with the activities due to the applicability of this issue and meaning to their lives. Thus, the issue were assimilated by the students far beyond what the proposed plan. The classes were attended with free will, joy and effectiveness, and concern yourself with the process and not with the results. This subject lends to global personal education in that works, including historical and cultural factors, explores creativity, body awareness and of itself, respect of differences and individual limitations. Therefore, the richness of this subject is be able to develop and identify some important issue, such as health, welfare, happiness, prejudice, solidarity, limits.
\end{abstract}

Keywords: Hip Hop, High School, Physical Education, Education.

\title{
Conhecendo a temática
}

Este relato de experiência traz como tema central a Cultura Hip Hop. A Cultura Hip Hop é utilizada como meio de inclusão social e cultural. Jovens de diversas idades e níveis sociais têm se apropriado desta cultura no seu cotidiano com roupas, dança, arte, música e estilo. Nos últimos anos este assunto está em evidência na nossa sociedade. Reportagens de televisão, novelas, filmes e até mesmo grandes empresas têm usado este assunto como tema de seus comerciais para anunciar os seus produtos. Porém, a Cultura Hip Hop vai além destes conceitos estabelecidos pela mídia internacional.

Segundo Reckziegel (2005), a Cultura Hip Hop surgiu nos guetos norte-americanos na mesma época em que era sólido o movimento dos 'Panteras Negras', que defendiam o 'Black Power' (poder negro). Um de seus idealizadores foi o jovem Kevin 
Donovan. Cansado das violentas e sangrentas guerras travadas pelas gangues do seu bairro (Bronx, Nova Iorque), Kevin e seus amigos começaram a substituí-las por batalhas de dança, nos festivais de Hip Hop da época, as famosas Batalhas de Break, disputadas durante as Block Parties.

As Block Parties eram festas realizadas nas ruas do Bronx, onde Kevin, mais conhecido como Afrika Bambaataa conheceu o imigrante jamaicano Kool Herc, que usava um toca-discos e pick-ups para fazer o break (a quebra) na música, nascia aí a figura do DJ.

Nessas festas ao ar livre também aconteciam as batalhas de dança travadas pelos b-boys ou breaker-boys, que dançavam no break da música, ao mesmo tempo que artistas pintavam panfletos e distribuíam nas ruas para divulgar as festas; com o avanço da tecnologia e o surgimento de sprays, esses artistas passaram a fazer sua arte não apenas em panfletos, mas também em paredões das ruas dos bairros negros e latinos.

Nasciam então os quatro elementos da Cultura Hip Hop: o $M C$, o DJ, o b-boy/b-girl e o grafite. Segundo Athayde (2008), o $M C$ (ou mestre de cerimônia) é a voz ouvida durante os festivais da Hip Hop, pois ele fica narrando todas as ações das batalhas de b-boys, faz comentários sobre a música que o DJ está tocando e sobre participantes do evento, com o objetivo de criar uma maior interação dentro do festival. Ele fica responsável por manter a animação, reforçar o repertório dos $D J$ 's, passar informativos do evento e as informações mais importantes, sinaliza também a urgência médica em algum atendimento aos participantes.

A música dita o ritmo dos eventos e por isso é muito importante, o DJ, também conhecido como disc jockey (ou dee jay), seleciona e toca as músicas que rolam nos eventos de Hip Hop. Normalmente o som que rola é o Rap. O DJ está sempre em sintonia com o $M C$ de quadra, contribuindo para a animação do público.

Dançarinos, mais conhecidos como breaker boys (ou $b$ boys) e b-girls desempenham o papel de simbolizar a situação 
de mutilação a que está submetido o povo pobre, sejam pelas guerras, pelos desempregos, pelas drogas ou pelas desigualdades sociais. Realizando movimentos "de quebrar" (to break), esses(as) dançarinos(as) demonstram o desejo das comunidades em romper culturalmente com o sistema opressor e explorador, bem como o seu anseio por um mundo melhor. Geralmente fazem isso através de pantomimas - arte de narrar fatos, situações, usando somente a expressão corporal, sem falar absolutamente nada.

Os artistas visuais urbanos (grafiteiros) aproveitam os espaços públicos para interferir culturalmente na decoração da cidade. Suas obras costumam ter um caráter poético-político e compreendem desde pequenos rabiscos até grandes murais executados em espaços especialmente designados para tal. A arte do graffiti está presente nos eventos de Hip Hop e também em diversos locais nas grandes cidades, cadernos escolares, embalagens com telas e painéis.

No começo a cultura Hip Hop tentava passar por cima da realidade dos negros nova-iorquinos, que eram pobres, além de serem amplamente discriminados racialmente. Eles se vestiam com roupas de marca, correntões, cheios de bijuterias e pares de tênis bonitos, tudo falsificado.

Hoje a cultura Hip Hop tem muitos adeptos no mundo todo. No Brasil, serve de refúgio para jovens de periferia ajudando-os a conscientizarem-se de seus papéis na sociedade, a entender a importância de seguir um caminho bom, longe das drogas, do álcool e do crime. Já nos Estados Unidos (EUA), os jovens enxergam o Hip-Hop como meio de ascensão social.

Fradique (2003) identifica o Hip Hop como um movimento cultural, e aponta como um de seus elementos indicadores a emergência de uma ideologia com o objetivo de criar diretrizes para um modo de vida (de rua) que seja contra a violência e utilizada como alternativa à rivalidade entre os grupos/gangues.

Para Gohn (1999), o Hip Hop caracteriza-se como um movimento que atrai os jovens, conduzindo-os a um engajamento político-social, com o objetivo de construir ou começar 
uma vida digna para si, e resgatar crianças e adolescentes em situação de risco.

Ao referir-se a essa questão Reckziegel (2005) constata que os jovens b-boys da Restinga, quando envolvidos em um grupo de dança, começam a tomar consciência de sua realidade social, a tentar agir sobre ela e a ela resistir.

\section{A experiência no CAp e considerações}

Segundo os PCNs (Parâmetros Curriculares Nacionais), no Ensino fundamental a criança deve aprender nas aulas de Educação Física, respectivamente, esporte, jogos, lutas, ginásticas e dança. Tendo como tema transversal, respectivamente, ética, saúde, meio ambiente, orientação sexual, pluraridade cultural, trabalho e consumo.

O professor de Educação Física deve buscar meios para proporcionar a prática corporal desses conteúdos e temas transversais visando à formação dos aspectos físicos, cognitivos, afetivos e psicossociais. Incluir os alunos nas atividades, não somente como reprodutores de gestos motores e teorias, mas incluí-los tentando constituir um ambiente de aprendizagem significativa, que faça sentido para o aluno, no qual ele tenha a possibilidade de fazer escolhas, trocar informações, estabelecer questões e construir hipóteses que vão impulsionar o seu saber. É de suma importância que a aula, ambiente onde ocorrem os processos de ensino e de aprendizagem, tenha significado para ele.

Os PCNEM não trazem nenhuma recomendação sobre o ministrar aulas de dança nas aulas de Educação Física, mas sim sobre esportes, saúde pública e ginástica. No mesmo documento podemos ver claras instruçóes acerca da dança nas aulas de Artes.

Apesar de não estar como um conteúdo da Educação Física no Ensino Médio, acredita-se que um professor de artes não possui bagagem acadêmica para ministrar aulas de dança, exceto nos casos em que esse tenha vivenciado alguma modalidade ou 
estilo durante sua vida e/ou realizado a formação em um curso específico. Ao contrário do professor de Educação Física, que, durante o período acadêmico, tem diversas experiências com dança em disciplinas e cursos extracurriculares.

Embora não haja uma definição clara sobre de quem é a responsabilidade de desenvolver tal conteúdo na escola, os PCN's reconhecem a sua importância na formação, apontando para os seguintes objetivos:

1. Analisar crítica e esteticamente músicas de gêneros, estilos e culturas diferenciadas;

2. Experimentar diversos ritmos e danças, bem como aprender a percerber as relações entre as diferentes fontes utilizadas nas composiçôes e os diversos significados (pessoais, culturais, políticos) articulados e veiculados nas danças criadas;

3. Observar e trabalhar a relação de cooperação e respeito entre as escolhas individuais e grupais em sala de aula, que ocorrem nos diferentes processos do fazer e do apreciar a dança.

Segundo Nanni (2003), o ser humano, através da dança, representa os seus sentimentos mais íntimos, utilizando-se de expressões corporais ritmadas que mantém estreita relação com a religiosidade/misticismo, a energia e a sexualidade, a ludicidade e o prazer. Diz ainda que é universal a necessidade de expressão corporal e que esta vai depender de cada cultura, sendo uma atividade social que objetiva integração grupal.

Dentro da escola são poucas as oportunidades que os alunos têm de serem inseridos em uma cultura, devido à pluralidade cultural e a formalidade de seus objetivos. A cultura Hip Hop é um dos grandes pilares da cultura urbana, possui milhares de adeptos e se faz muito presente em bairros de periferia. Por se tratar de uma cultura oriunda dos guetos norte-americanos, a cultura Hip Hop é muito bem aceita em bairros de periferia e vilas. A dança na escola, então, torna-se um poderoso instrumento de aproximação entre a cultura popular e o conteúdo 
formal desenvolvido na escola, principalmente nas instituições públicas onde se encontram a maioria desfavorecida.

O estudo realizado por Ribeiro (2008), intitulado "Hiphopologia: o que dizem pesquisadores brasileiros sobre o hip hop na escola?", revelou que apesar dos riscos, desafios e tensões a serem enfrentadas, o Hip Hop é visto como possibilidade, proposta e inclusão de várias questões do currículo escolar e que, embora seja um assunto relevante e instigador, não deve ser visto como "salvador" e agente transformador do mundo, como para muitos desse movimento.

Ao reconhecer dessa forma, nasceu a idéia de elaborar um plano de ensino, no Estágio Curricular de Docência do Curso de Educação Física da UFRGS, com a temática do Hip Hop como centro de todas as ações durante o semestre. Esse plano foi recebido com muita alegria, tanto pela coordenadora de estágio, quanto pela professora da disciplina de Educação Física do Colégio de Aplicação (CAp) da mesma universidade.

Primeiramente buscou-se trabalhar a dança, um conteúdo específico da cultura corporal do movimento humano, através da Cultura Hip Hop, considerando os quatro elementos da CUFA (Central Única das Favelas), a qual trata o Hip-Hop como centro das atenções em eventos. São elementos da Cultura Hip Hop o Mc (mestre de cerimônia), o DJ (disk-jokey), o b-boy/b-girl (breakerboy/girl) e o grafitti.

Embora esses elementos já tenham sido abordados neste relato, vale (re)lembrar a função de cada um deles. O Mc é o reponsável por animar as festas embates de Hip Hop, rima com facilidade e garante a diversão do público. $\mathrm{O} D J$ é o responsável por mixar as batidas, ajudar o Mc na animação da festa e a marcar o ritmo dos b-boys. Os b-boys são os reponsáveis pela dança, são caracterizados por movimentos de robô, parafusos no chão, danças de quebras e contorcionismos. E, finalmente, os grafiteiros são responsáveis por divulgar as festas com desenhos e pôsteres, através de mensagens chamativas e de cunho artístico. 
A intenção foi possibilitar aos alunos uma vivência do universo da Cultura Hip Hop através da dança. Foram usados exercícios educativos introdutórios, passos marcados e a dança propriamente dita. Sempre antes de começar a aula e após seu término, foram realizadas reflexóes. Sobre a aula passada - no início - e sobre o que aconteceu na aula do dia - no fim.

A turma foi composta 27 alunos - sendo 25 meninas e 02 meninos - com idade entre 16 e 18 anos, de todas as classes sociais, bastante agitados, empolgados, respeitadores, corporalmente e cognitivamente bastante avançados, talvez devido à prática exercida na Educação Física do CAp. Ao todo foram ministradas 26 aulas, 3 períodos por semana - sendo dois períodos nas segundas-feiras e um nas quintas-feiras.

As aulas aconteceram da seguinte forma:

$\mathrm{Na}$ primeira aula foi dada uma breve introdução sobre o que é a Cultura Hip Hop, o que seria trabalhado na disciplina e em que contexto histórico e político essa cultura foi criada. Muitos deles não sabiam que a cultura Hip Hop estava, no início, atrelada aos movimentos revolucionários dos negros norte-americanos. Eles ficaram empolgados ao escutarem a história dos "Panteras Negras" que defendiam o Black Power (poder ao povo negro), ao ouvirem "minibiografias" de grandes nomes da revolução negra como Malcom X e M. Luther King. Ao escutar a história de forma resumida, um aluno constatou: "Então é por isso que eles usavam aqueles cabelóes!”.

A aula seguinte foi muito contagiante, pois todos os alunos foram caracterizados (roupas no estilo Hip Hop) e estavam muito motivados para a prática. Isto pode ter ocorrido pelo fato de o professor conhecer a maioria dos alunos, devido a outras experiências de docência no CAp/UFRGS. Primeiramente, dedicou-se ao aprendizado de passos básicos e dissociados do Hip Hop, porém, essenciais para avançar o aprendizado. Sempre no processo do mais simples para o mais complexo, conforme a taxionomia. $\mathrm{O}$ objetivo era chegar ao último estágio, no qual o aluno conseguiria criar ou recriar o que havia assimilado, e 
pudesse vivenciar uma apresentação de suas aprendizagens frente a um grande público.

Depois dessa primeira aula prática, nossas expectativas com relação ao desenvolvimento do plano de ensino elaborado foram as melhores possíveis, e de fato, confirmadas no decorrer do semestre.

Apenas em ocasiões especiais os alunos faltavam às aulas ou deixavam de participar. Diferente das outras experiências que tivemos como professores de Educação Física onde existiam frequentemente problemas que impediam a continuidade do trabalho em aula, como por exemplo: meninas com cólicas, alunos com dor de cabeça, muitas idas ao banheiro ou para tomar água, entre outros muitas vezes criados por aqueles alunos desmotivados com a atividade.

Sabe-se que a motivação do adolescente no contexto escolar é um fenômeno complexo devido à diversidade de fatores, entre eles a relação com o professor. Nesse sentido pode ser considerado um processo ativo que integra fatores internos e externos (SANTOS et al., 2010).

Para ilustrar o exposto e demonstrar o quanto essa experiência de alguma forma contribuiu para motivar a participação em aula, frases como estas surgiram: - "Bah, ô sor, tô tri mal hoje! Só vim porque é a tua aula" e na expressão: - "Ah! Não te faz de loca, vem pra aula e pára de dar 'migué', a gente te conhece". Logo o esforço individual e o incentivo coletivo encontram-se respectivamente representados na fala dos alunos.

De certa forma, essas atitudes espontâneas dos alunos (pois o professor nunca obrigou a participar das aulas) estimulavam o professor com os processos de ensino e de aprendizagem, que se disponibilizava a ficar após o horário da aula, para quem tivesse com dificuldades ou quem quisesse apenas dançar mais um pouco. Essa atitude provocada pelos alunos - que pediam para o professor permanecer ensinando além do horário estipulado - chamou a atenção do professor com relação ao interesse e comprometimento deles com o conteúdo, pois a aula terminava 
impreterivelmente às 12 horas e 10 minutos, após os alunos podiam ir para casa ou usar esse tempo na escola para se alimentar, conversar, relaxar um pouco.

Também nesse sentido, em várias aulas os alunos comentavam com o professor que, durante a festa no fim de semana, eles foram evidenciados por realizar os passos aprendidos durante as aulas, e alguns deles diziam que treinavam os passos em casa. Isso acontecia frequentemente e com uma boa porcentagem da turma. As expressões mais frequentes eram: “- Bah, sôr $r$ O passo da aula passada era difícil, tive que treinar em casa" e "- Arrasei na festa com aquele passo que aprendi. Todos ficaram olhando."

Diante do exposto, constata-se que o conteúdo ministrado nessa proposta fazia parte do cotidiano dos alunos, e por isso, passa a ocupar um espaço relevante na vida desses estudantes. $\mathrm{O}$ fato de "treinar os passos em casa" significa que o aluno percebe o valor significativo dessa aprendizagem para a vida dele. Sabese que é extremamente importante o sentido e/ou significado atribuído pelos alunos com relação aos conteúdos para elevar o seu envolvimento com os processos de ensino e de aprendizagem.

Isso significa que, durante o tempo da aula, eles (que treinaram o passo em casa) não haviam assimilado o conteúdo devido a sua complexidade, e se dedicavam a aprendê-lo em casa porque o julgaram importante e percebiam sua aplicabilidade.

Ao chegar à próxima aula, os alunos desejavam mostrar ao professor que aprenderam e que podiam passar para outro passo mais complexo. Nesse ritmo, acabou-se por ensinar até os passos que se realizam no chão (os de maior dificuldade), passos que exigem muita força nos braços e pernas, equilíbrio, flexibilidade e agilidade.

Na medida em que se avançava no conteúdo, percebia-se um maior envolvimento por parte dos alunos e novas exigências foram surgindo e sendo sugeridas por eles. Alguns até pediram para que o professor gravasse um CD com músicas de Hip Hop para poder escutar, treinar, criar, enfim, colocar em prática aquilo que estavam aprendendo. 
Dessa forma, constatou-se que os conteúdos assimilados pelos alunos foram muito além do que o planejamento propôs. Cada etapa foi ensinada de forma gradual e pedagógica, respeitando o ritmo e as limitaçóes da turma, ou seja, os primeiros passos envolvendo, no máximo, uma ou duas articulações, para no fim, ensinar os mais difíceis, que envolviam a maioria das articulações do corpo.

Aqueles que tinham facilidade de assimilar as instruções do professor ajudavam os que não tinham tanta facilidade assim, agindo como se fossem monitores, de modo que eles, ao serem motivados e assistidos, não abandonaram a modalidade.

De fato os alunos não foram avaliados pelo desempenho em aula, e sim pela assiduidade, participação e comportamento. Embora não tenha sido utilizado um instrumento para verificar o porquê dessa participação maciça, e, algumas pessoas possam pensar que os critérios de avaliação conduziram a esse resultado, percebia-se que os alunos frequentavam as aulas com espontaneidade, efetividade e alegria, demonstrando pouca ou nenhuma preocupação com o que estava sendo avaliado.

No fim do semestre houve uma apresentação para os colegas das outras modalidades da Educação Física e, no fim do ano, outra para a comunidade escolar. Para apresentação o professor montou uma coreografia e deu oportunidade para os alunos criarem uma sequência de passos em uma frase musical. Foram criadas 04 sequências de passos pelos alunos, o que possibilitou atingir o principal objetivo estabelecido, no qual os alunos ao final do semestre pudessem criar a sua própria dança, seus próprios passos, seu estilo.

Assim, diante dos resultados apresentados, principalmente pelas falas, expressões e participação dos alunos, o Hip Hop demonstrou ser um conteúdo possível na disciplina de Educação Física escolar do ensino médio, pois através dele foi possível desenvolver os objetivos pré-estabelecidos.

Como qualquer conteúdo curricular, se presta a formação global/integral do indivíduo na medida em que trabalha com 
aspectos histórico-culturais, explora o movimento criativo, o conhecimento do corpo e de si, desafia o respeito às diferenças e às limitações, trabalha diferentes ritmos, entre outros.

Portanto, diante da riqueza que esse conteúdo é capaz de desenvolver identificam-se aqui alguns conceitos, que contribuem para a vida e que fazem do Hip Hop uma alternativa curricular, tanto na disciplina de Educação Física quanto em algumas atividades complementares que acontecem nas instituições educacionais, tais como saúde, bem-estar, felicidade, preconceito, solidariedade, limites, entre outros.

\section{Referências}

ATHAIDE, Celso. Manual dos basqueteiros. Rio de Janeiro: Central Única das Favelas, 2008.

BRASIL. Introdução aos parâmetros curriculares nacionais. Secretaria de Educação Fundamental. Brasília: MEC/SEF, 1997. 126p.

BRASIL. Parâmetros curriculares nacionais do ENSINO MÉDIO. Secretaria de Educação Fundamental. - Brasília: MEC/SEF, 2000.

CENTRAL ÚNICA DAS FAVELAS. [s.d]. CUFA. Disponível em http:// www.cufa.org.br/. Acesso em 10 de jul. 2009.

FRADIQUE, Teresa. Fixar o movimento nas margens do rio: duas experiências de construção de um objeto de estudo em terreno urbano em Portugal. In: VELHO, Gilberto; KUSCHNIR, Karina (Orgs.). Pesquisas urbanas: desafios do trabalho antropológico. Rio de Janeiro: Jorge Zahar, p. 90-117, 2003.

GOHN, Maria da Glória. Educação não-formal e cultura política: Impacto sobre o associativismo do terceiro setor. São Paulo: Cortez, 1999.

NANNI, Dionísia. Ensino da dança. Rio de Janeiro: Shape, 2003. Disponivel em portal.mec.gov.br/seb/arquivos/pdf/blegais.pdf. Acesso em 4 de mar. 2009.

RECKZIEGEL, Ana. Dança de rua: opção pela dignidade e compromisso social. Movimento, Porto Alegre, v. 11, n. 2, p. 59-73, maio/ago. 2005. 
RIBEIRO, William de Góes. Hiphopologia: o que dizem pesquisadores brasileiros sobre o hip hop na escola? In: Reunião anual da ANPED, v. 31. Grupo de trabalhos - GT 21 - Afro-Brasileiros e Educação. Associação Nacional de Pós-Graduação e Pesquisa em Educação, 2008.

SANTOS, Bettina; ANTUNES, Denise; BERNARDI, Jussara; GATTO, Gabriela. Na adolescência, o Processo Motivacional e a Informática. In: SANTOS, Bettina; CARREÑO, Ángel (Orgs.). A motivação em diferentes Cenários. Porto Alegre: EdiPUCRS, 2010. 